\title{
Expert group to look at UK cloning law ...
}

[LONDON] The British government has said that it needs more time before deciding whether to allow cloning techniques - such as the technology that produced Dolly the sheep - to be used on human embryos.

An expert advisory group, chaired by the government's chief medical officer Liam Donaldson, is to be set up to consider the risks and benefits of such research. The group will scour the literature and seek the views of research institutions to establish evidence for potential health benefits of the technology. Its findings will be presented early next year to the government and to the newly formed Human Genetics Commission.

The decision to set up the expert group is a response to calls for the Human Fertilisation and Embryology Act of 1990, which bans the use of cloning techniques on human embryos, to allow what is being described as "therapeutic cloning".

The proposed changes to the law were suggested at the end of last year by the government's Human Genetics Advisory Com-

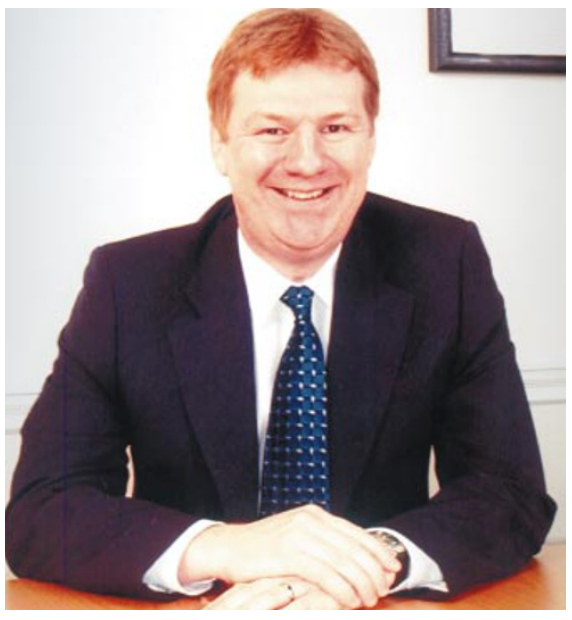

Donaldson: "we need to proceed carefully."

mission (HGAC) and the Human Fertilisation and Embryology Authority (HFEA), the statutory body responsible for overseeing certain fertility treatments and human embryo research.

"When the 1990 act was passed, the

\section{-.. as US DNA advisory body redefines itself}

[WASHINGTON] The US federal committee that debates new gene-therapy protocols is proposing to expand its remit beyond just experiments involving recombinant DNA.

The Recombinant DNA Advisory Committee (RAC) of the National Institutes of Health (NIH) plans to publish a new definition of recombinant DNA this summer in the Federal Register, for discussion and possible adoption at a meeting in September.

The change could broaden the committee's charge to reflect a changing and widening field in which an increasing variety of gene-manipulation technologies are challenging traditional notions of genetic engineering.

For instance, technologies are emerging for exploiting RNA - molecules involved in passing on the messages encoded in genes for purposes such as blocking viral gene transcription. And it is hoped that oligonucleotides, which are tiny stretches of machine-made DNA, may soon be used to correct inherited diseases by substituting for a deficient gene.

A 1976 definition still used by the RAC defines recombinant DNA as "molecules that are constructed outside living cells by joining natural or synthetic DNA segments to DNA molecules that can replicate in a living cell". Experiments that the RAC should monitor, its guidelines say, are those "involving the deliberate transfer of recombinant DNA into human subjects”.
"We have not changed the NIH language to keep up to date with new technologies," says Claudia Mickelson, the biosafety officer at the Massachusetts Institute of Technology, who chairs the RAC. The new definition, she says, is part of an effort to make the RAC's guidelines "more accurately reflect the state of molecular biology and genetic engineering in the labs".

A RAC working group that is developing the new definition is working from a far broader 1993 Food and Drug Administration (FDA) policy, which defines gene therapy as "the administration of genetic material in order to modify or manipulate the expression of a gene product, or to alter the biological properties of living cells". It says that gene-transfer experiments include a variety of technologies, ranging from giving patients stem cells modified with a viral vector to using oligonucleotides to correct genetic mutations.

The FDA definition includes cloning, theoretically at least, and is part of the grounds on which the agency asserted its jurisdiction over that area last year (see Nature 391, 318; 1998). But Mickelson says that the RAC has no intention of getting involved with cloning issues.

Phil Noguchi, director of the Division of Cellular and Gene Therapies at the FDA, calls the RAC's move to amend the definition "very healthy", adding that "public discussion of these things needs to always be at the cutting edge". beneficial therapeutic consequences that could potentially result from human embryo research were not envisaged," the two organizations stated in a recent jointly issued report, Cloning Issues in Reproduction, Science and Medicine.

The HFEA/HGAC report calls for cloning techniques to be permit-ted on human embryos less than 14 days old for the development of treatments for mitochondrial disease, and for treatments for diseased or damaged tissues or organs.

But in its response to parliament last week, the government reiterated its opposition to cloning for reproductive purposes. It said it still needed to be convinced of the need for a change to the law to allow therapeutic cloning.

"It has been suggested that therapeutic cloning techniques might be able to provide immunologically compatible tissue for the treatment of degenerative diseases of the heart, kidneys and cerebral tissue, or repair damage to skin and bone," said Tessa Jowell, the health minister. "We believe that more evidence is required for the need for such research, its potential benefits and risks, and that account should be taken of alternative approaches that might achieve the same ends."

Donaldson says that the government is in no rush to proceed, since it recognizes that there is considerable public concern over issues such as cloning and research on human embryos. "We need to proceed carefully," he says.

He dismisses claims that delays in licensing research on human embryos would drive British scientists to the United States. "I hardly think there'll be a brain drain in the next six months." The government has rejected a suggestion in the HFEA/HGAC report to introduce legislation that specifically outlaws all forms of human reproductive cloning, choosing instead to review the matter in five years' time.

An official from the Department of Health says that the government sees no reason to change the law at present. This is partly because the prospect of successful reproductive human cloning remains uncertain, but also because it believes the existing law is strong enough.

The HFEA/HGAC suggestion was prompted because the law currently prohibits just one type of cloning - the nuclear substitution of any cell while it forms part of an embryo. The technique that was used to create Dolly involves nuclear transfer into an egg, not into an embryo. But both the HFEA and the government believe that the existing law is broad enough to prevent the use of nuclear transfer in an unfertilized egg.
EhsanMasood 